
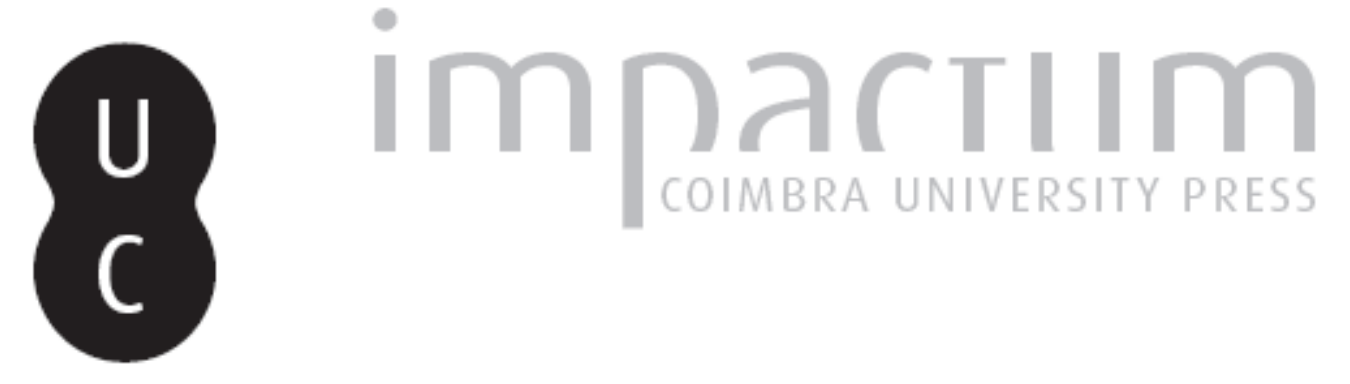

\title{
Covelo do Gerês: contributo para o estudo dos movimentos de massa no Norte de Portugal
}

\author{
Autor(es): $\quad$ Pedrosa, A. Sousa; Bateira, C. Meneses; Soares, L. Pinheiro \\ Publicado por: Associação Portuguesa de Riscos, Prevenção e Segurança \\ URL \\ persistente: \\ URI:http://hdl.handle.net/10316.2/40177 \\ DOI: \\ DOI:https://doi.org/10.14195/1647-7723_2_3
}

Accessed : $\quad$ 26-Apr-2023 13:20:19

A navegação consulta e descarregamento dos títulos inseridos nas Bibliotecas Digitais UC Digitalis, UC Pombalina e UC Impactum, pressupõem a aceitação plena e sem reservas dos Termos e Condições de Uso destas Bibliotecas Digitais, disponíveis em https://digitalis.uc.pt/pt-pt/termos.

Conforme exposto nos referidos Termos e Condições de Uso, o descarregamento de títulos de acesso restrito requer uma licença válida de autorização devendo o utilizador aceder ao(s) documento(s) a partir de um endereço de IP da instituição detentora da supramencionada licença.

Ao utilizador é apenas permitido o descarregamento para uso pessoal, pelo que o emprego do(s) título(s) descarregado(s) para outro fim, designadamente comercial, carece de autorização do respetivo autor ou editor da obra.

Na medida em que todas as obras da UC Digitalis se encontram protegidas pelo Código do Direito de Autor e Direitos Conexos e demais legislação aplicável, toda a cópia, parcial ou total, deste documento, nos casos em que é legalmente admitida, deverá conter ou fazer-se acompanhar por este aviso.






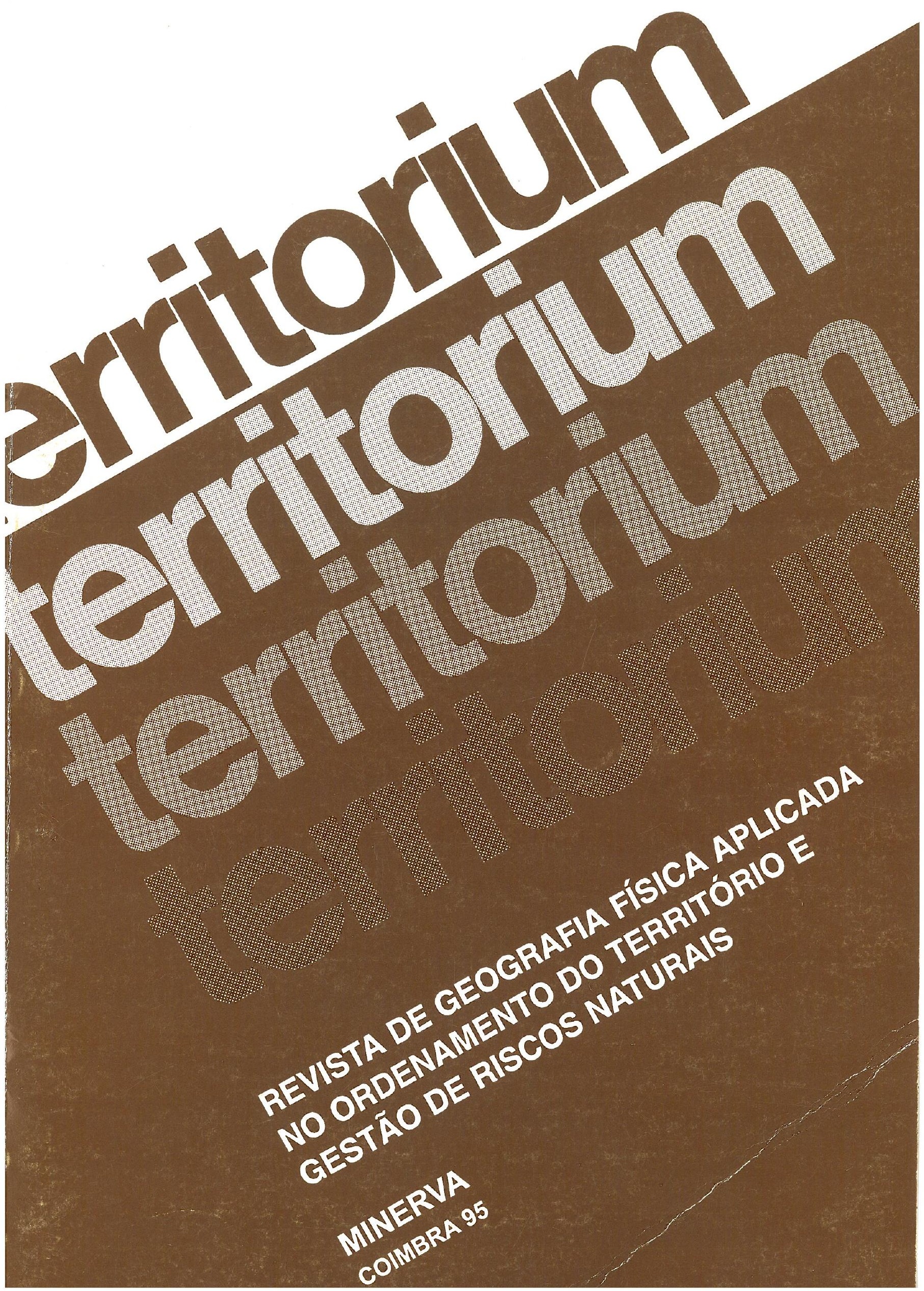




\section{Covelo do Gerês: \\ Contributo para o estudo dos movimentos de massa no Norte de Portugal.}

\section{A. Sousa Pedrosa . \\ C. Meneses Bateira * \\ L. Pinheiro Soares "*}

\section{Resumo:}

Quase 30 anos depois, ainda hoje se podem observar importantes vestígios do grande movimento de terras verificado em Covelo do Gerês. No presente artigo, descreve-se o processo e discutem-se as condiçōes que se revelaram favoráveis à sua ocorrência.

Palavras chave:

Noroeste de Portugal, Geomorfologia, movimentos de massa, riscos.

\section{Résumé:}

Presque 30 ans après son déclenchement, on peut encore observer des vestiges très importants du grand mouvement de terrain du Covelo de Gerês. Dans cet article on décrit le processus et on discute les conditions considérées favorables pour sa génèse et développement.

Mots clés:

Nord-ouest du Portugal, Géomorphologie, mouvements de terrain, risques.

\section{Abstract:}

Almost 30 years later, we can still see some aspects of the Covelo do Gerês landslide. In this paper, the authors describe the processes and discuss the favourable conditions to its occurrence.

Key words:

Northwest of Portugal, Geomorphology, landslides, risks.

\section{IN'TRODUÇÃo}

O estudo sistemático de movimentos de massa no Norte de Portugal, com o objectivo de definir as condições hidroclimáticas, geomorfológicas e antrópicas que propiciam a sua ocorrência, faz parte de um projecto que pretendemos implementar como contributo para o Planeamento Físico. Este estudo visa a recolha de elementos que permitam definir e cartografaráreas de risco potencial ao desenvolvimento de tais processos, constituindo um instrumento de trabalho extremamente útil para as entidades directamente envolvidas no planeamento e ordenamento do território.

Após o estudo do caso de Cavez - Cabeceiras de Basto (A. PEDROSA, B. MARQUES,1994; C. BATEIRA, L. SOARES, 1992), responsável pela morte de 15 pessoas em Dezembro de 1981, o

* Professor Auxiliar. Instituto de Geografia. Faculdade de Letras. Universidade do Porto

** Assistente. Instituto de Geografia. Faculdade de Letras. Universidade do Porto movimento ocorrido em Covêlo do Gerês (fig. 1) atraiu a nossa atenção pela sua espectacularidade que, passados quase trinta anos, é bem visível no terreno.

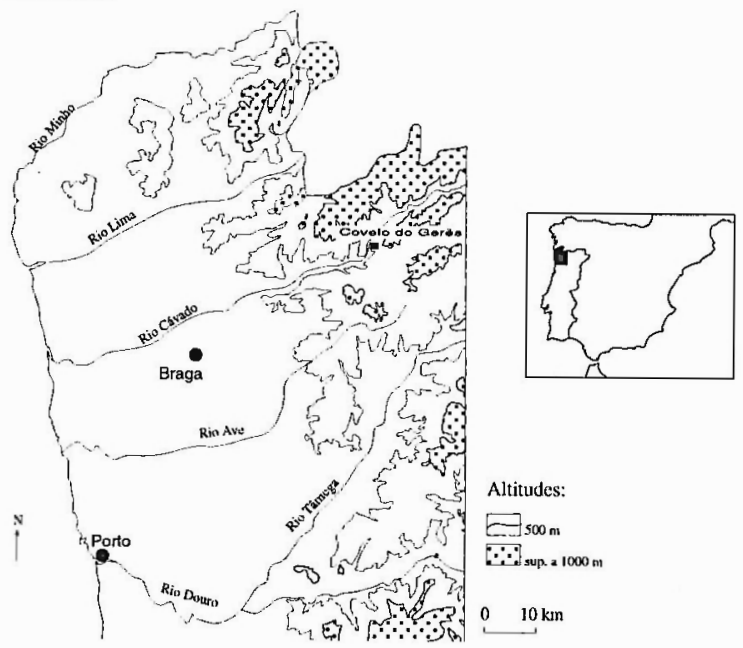

Fig. 1 - Localização da área em estudo. 
Inserida em plena Serra do Gerês, uma das mais vigorosas do NW de Portugal (1500 m), esta pequena freguesia do concelho de Montalegre desenvolve-se ao longo da vertente oriental do rio Cávado, entre as albufeiras de Paradela e Venda Nova. Trata-se de um aglomerado populacional de dimensões reduzidas, verificando-se que o sector específico em que ocorreu o movimento, corresponde principalmente ao lugar de Sapateira.

\section{Características e descrição do Processo}

\section{Ocorrência e fases de evolução}

Segundo informações recolhidas no local e nos jornais diários da época (1966), o processo desenvolveu-se ao longo de vários dias, iniciando-se a 10 de Fevereiro e prolongando-se até ao dia 22 . As primeiras movimentações foram de pequena dimensão, o que permitiu colocar de sobreaviso os habitantes que começaram a abandonar as suas casas. Tal evitou uma catástrofe provavelmente superior à de Cavez, limitando as consequências a perdas de carácter económico.

No dia 16 do mesmo mês, verificou-se um movimento de terras de maiores dimensões: uma "onda" de lama e detritos rapidamente alastrou sobre a aldeia, submergindo 8 casas e invadindo os terrenos de cultivo mais próximos. A sua violência foi de tal ordem, que arrastou núcleos de folhosas e blocos de granito com um diâmetro superior a $3 \mathrm{~m}$, destruindo igualmente a estrada que liga Paradela a Covelo.

Nos dias 17 e 18 voltaram a registar-se novas ocorrências, mas de menor intensidade, até que a 22 de Fevereiro é noticiada a última movimentação.

É importante assinalar que a ocorrência do fluxo de detritos ao longo de vários dias, coincidiu com um período de fortes precipitações. Embora, adiante se pretenda analisar com mais pormenor esta questão, nos meses de Janeiro e Fevereiro destacam-se duas grandes sequências chuvosas (tendo sido registada uma precipitação de $97 \mathrm{~mm}$ num único dia em Paradela do Rio - a 6 km de distância em linha recta), entrecortados somente por um período menos húmido. Neste período intermédio, apenas se registaram quatro dias com ausência total de chuva e cinco dias com precipitação próxima dos $20 \mathrm{~mm}$. Assim, verificou-se uma constante acumulação de reservas de água no solo, o que sem dúvida contribuiu para o desenvolvimento do fluxo.

No entanto, a relação entre as diversas movimentações dos materiais e os dados de precipitação é complicada. Não estamos perante um movimento de massa simples, directamente relacionado com um único episódio chuvoso. A repetição do processo durante vários dias deve-se provavelmente a uma conjugação de factores, entre os quais as duas sequências de precipitações regulares e intensas são um elemento de destaque.

De realçar que, vários anos após a ocorrência do fluxo, se verificou a queda de blocos próximo da cicatriz principal. Este facto, aliado à existência de fendas abertas para montante, bem como ao rápido desenvolvimento de ravinamentos, leva-nos a considerar que estamos perante uma área de instabilidade geomorfológica persistente.

\section{Aspectos morfológicos do movimentode massa.}

Comoreferimos, o movimento de massa de Covelo do Gerês processou-se essencialmente no sector a montante de Sapateira, vencendo um desnível de aproximadamente $200 \mathrm{~m}$ e percorrendo uma distância que excede os $600 \mathrm{~m}^{(1)}$.

A cicatriz resultante apresenta grandes dimensões e uma forma complexa, evidenciando, no sector principal, uma largura superior a $40 \mathrm{~m}$ e mais de 50 de altura (fot. 1) No entanto, se nesta secção revela uma forma em arco, lateralmente a sua morfologia é bastante irregular, desenvolvendo-se como que cicatrizes secundárias de dimensões mais reduzidas (fig. 2). Este aspecto relaciona-se provavelmente com as condições estruturais da área, em especial com o facto da parte superior da cicatriz coincidir com o contacto entre os metassedimentos e o granito do Gerês, neste sector relativamente conservado. Pelo contrário, próximo das "cicatrizes secundárias" este granito evidencia uma profunda alteração, que poderá ser responsável pela irregularidade morfológica referida, dado o progressivo "deslizamento" das arenas graníticas.

O fluxo de detritos desenvolveu-se ao longo de uma ravina, regredindo de jusante para montante ao longo dos vários dias citados, permitindo o progressivo escavamento da área. Alguns sectores foram parcialmente preenchidos pelos materiais transportados, sendo visíveis alguns rebordos de acumulação. Aliás, parece-nos importante referir que, na área envolvente, é possível identificar depósitos de vertente preenchendo paleoravinamentos impressos no manto de alteração granítico, traduzindo provavelmente movimentações antigas, similares, embora de menor dimensão, às que ocorreram em 1966.

O material transportado extravasou largamente os limites do canal de escoamento prévio, invadindo os campos agrícolas mais próximos e "submergindo" parte do aglomerado populacional. Como já referimos,

(1) Refira-se, no entanto, que parte do material foi transportado pelo ribeiro dos Novainhos que corre no sopé da vertente e chegou a atingir o rio Cávado, situado a cerca de $2,5 \mathrm{Km}$ da área de ruptura. 


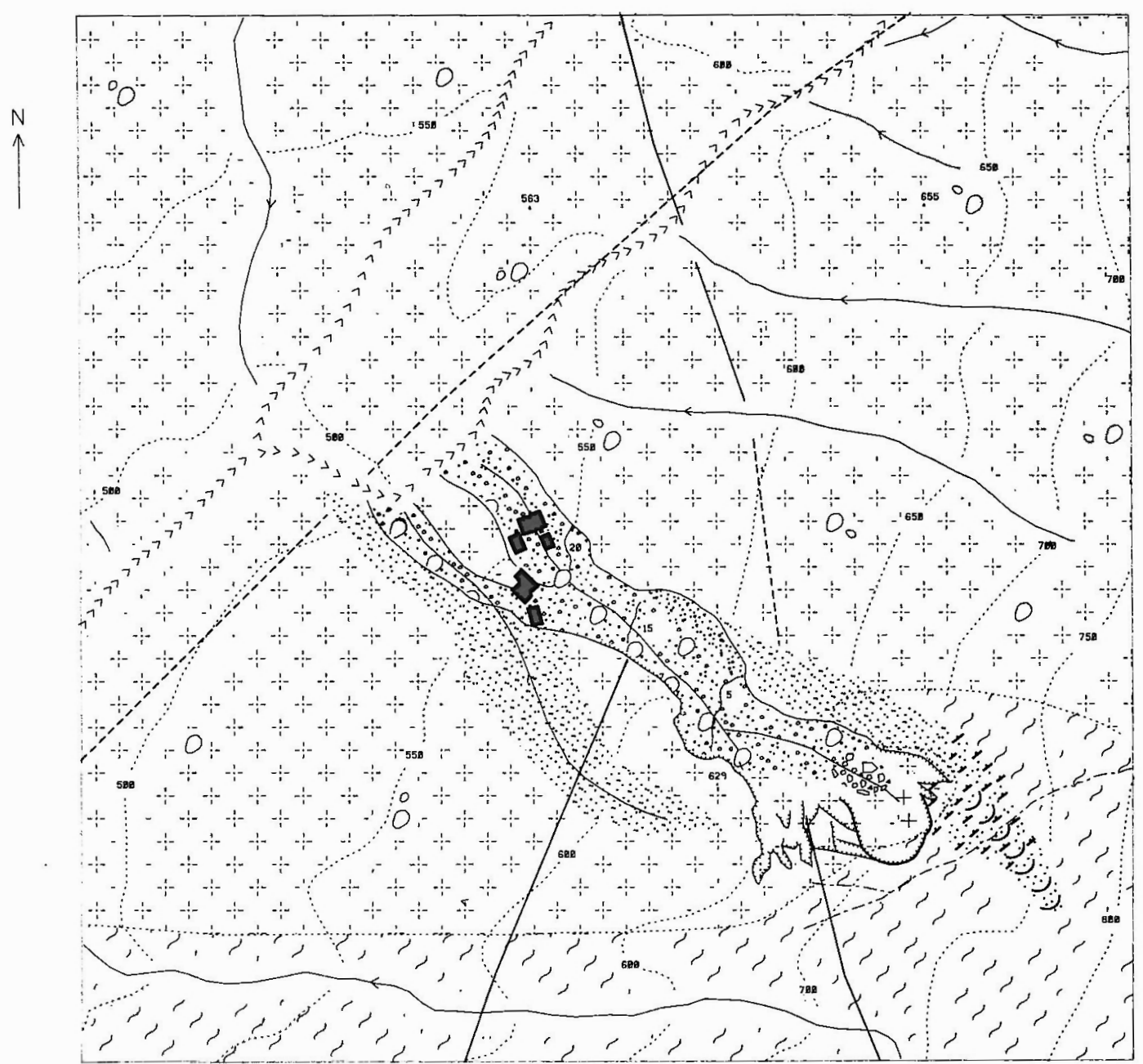

Fig. 2: Esboço geomorfológico do fluxo de detritos do Covelo do Gerês.
LEGENDA

$\stackrel{228}{2}$ 1. Ponto cotodo.

2. Curva de nível.

3. Cicatriz do fluxo de detritos com mais de $50 \mathrm{~m}$

4. Idem, com mais de $20 \mathrm{~m}$.

5. Limite do óreo de acumulecáo.

6. Fondas profundas.

7. Áreo com fendas superficiais.

B. Borranco

9. Vale om forme de $v$.

rece 10. vale en forma de berço.

20. 11. Rebordo de acumulaçso com oltura de $20 \mathrm{~m}$.

12. Bolos groniticos.

Fis

14. Detritos movimentados pelo fluxo

$\because \because 15$. Depósito de vertente orgiloso. 16. Granito do Gerês, muito alterado. 17. Grani to do Gerês. 18. Metosedimentos

19. Folho.

20. Folho provóvel.

21..... Limite Geológioo.

22. Cosas. 


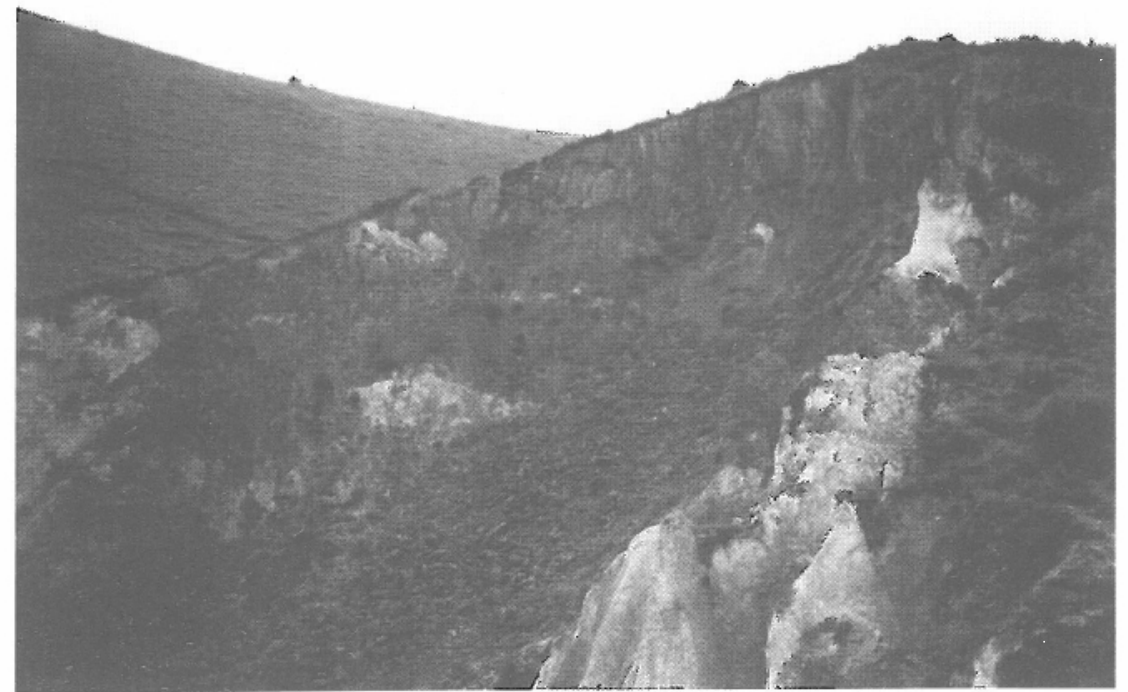

Fot. 1 - Cicatriz principal do fluxo de detritos de Covelo do Gerês. É visível, na parte superior da cicatriz, o afloramento de metassedimentos do Silúrico e, na parte inferior, o granito do Gerês, muito alterado.

conseguiu arrastar blocos de granito com uma dimensão superior a $3 \mathrm{~m}$ de diâmetro maior (fot. 2), embora seja nítido o domínio de materiais de menor calibre.

No entanto, a estrada que passa próximo da povoação constituiu, pela diminuição do declive, um patamar de sustentação do movimento, definindo o principal sector de acumulação. Mas tal não evitou a destruição de várias casas. Na parte mais a jusante, os materiais preencheram na totalidade o canal de transporte, transbordando para a ravina a $\mathrm{SW}$ e subdividindo-se em dois ramos o que mostra bem a importância do volume da carga deslocada.

\section{CONDIÇõES DE OCORRÊNCIA}

\section{Factores de ordem geológica}

Do ponto de vista estrutural, a área em estudo situa-se na Zona Centro Ibérica do Maciço Hespérico, mais precisamente na sub-zona da Galiza Média-Trás-os-Montes, constituindo uma das áreas de mais intensa deformação no contex to da orogenia hercínica (fig. 3).

Fot. 2 - Área de acumulação do fluxo de detritos, no sector mais a jusante. Em primeiro plano, bloco de granito com cerca de $4 \mathrm{~m}$ de eixo maior. Em segundo plano, depósito de acumulação com espessura superior a $20 \mathrm{~m}$.

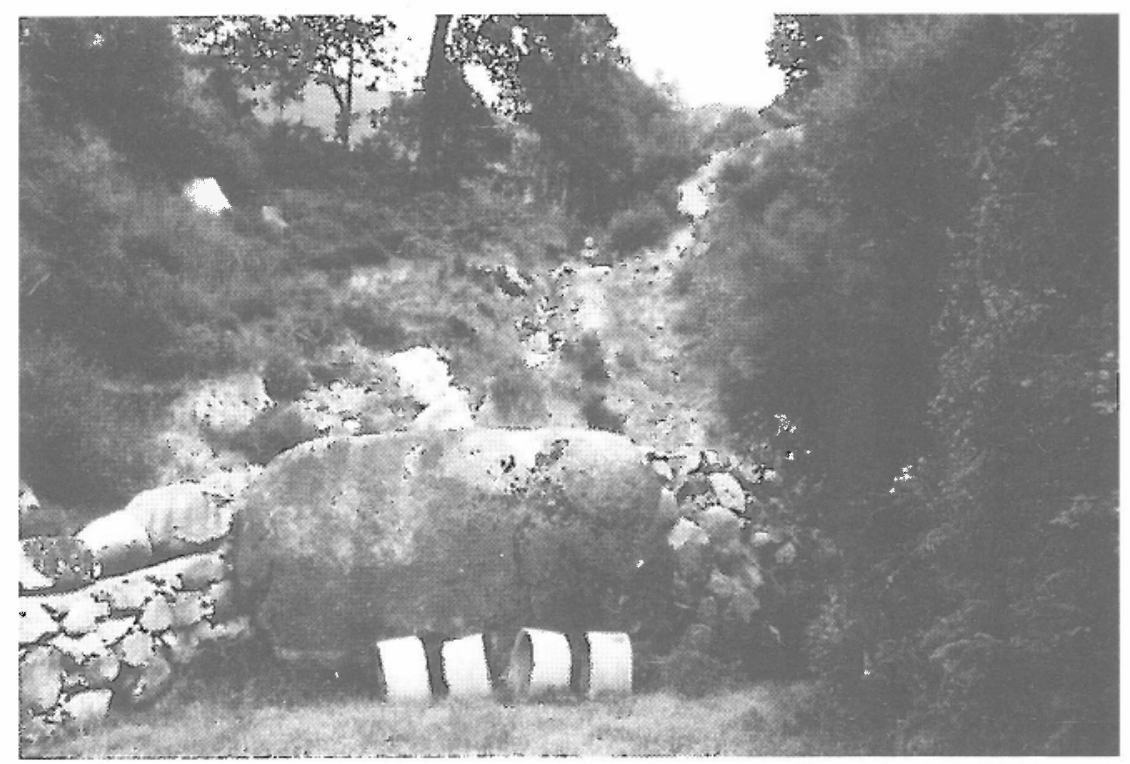




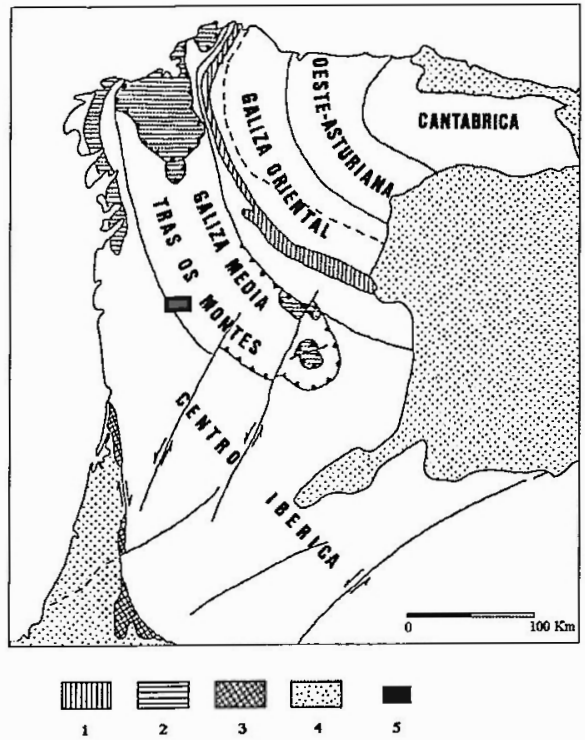

Fig. 3 - Enquadramento estrutural no NW da Península Ibérica. 1. Pré-Câmbrico do tipo "Ollo de Sapo" da Zona da Galiza Oriental; 2. Pré-Câmbrico em grande parte polimetamórfico das zonas da Galiza Média e Centro Ibérica; 3. Pré-Câmbrico polimetamórfico da zona de Ossa-Morena; 4. Cobertura secundária e terciária; 5. Folha 6-B da Carta Geológica de Portugal. Fonte: F. NORONHA, M.L. RIBEIRO, 1983.

No entanto, dada a sua localização no sector mais ocidental da referida sub-zona, as características do metamorfismo regional e do magmatismo aproximam-se mais das da zona Centro Ibérica. Assim, a um metamorfismo de alta pressão e à exiguidade de intrusões graníticas em Trás-osMontes Oriental, sucede um metamorfismo regional "(...) plurifacial et compris entre le type Barrovien et le type de Basse Pression(...) intimement lié au niveau des intrusions de granitoides", abundantes e pertencentes às séric alcalina e calcoalcalina (A. RIBEIRO et al, 1979, p.17).

Com efeito, litologicamente, a área em estudo é caracterizada pela presença de diversos tipos de granitóides hercínicos (que constituem cerca de $75 \%$ da área cartografada na folha $6 \mathrm{~B}$ da Carta Geológica de Portugal) e por metassedimentos do Silúrico, essencialmente xistos pelíticos (F. NORONHA; M.L. RIBEIRO, 1983).

No entanto, no sector onde ocorreu o movimento, distinguem-se basicamente dois tipos de rochas, cujo contacto se define precisamente na cicatriz do fluxo (fig. 4):

- Xistos pelíticos com raros níveis de xistos quartzíticos, apresentando uma granularidade média e forte foliação;

- Granito porfiróide de grão médio a grosseiro, com biotite dominante (Granito do Gerês).
No contexto dos granitóides da área, o granito do Gerês insere-se no grupo dos mais recentes, pós-tectónicos, de génese provavelmente associada à diferenciação de um magma básico de origem infracrustal (M.L.RIBEIRO, 1983). Tendo em conta a sua composição químico-mineralógica (Quadro ${ }^{\circ} 1$ ), podemos considerar que se trata de um granitóide de transição entre as séries alcalina e calco-alcalina, ou seja, essencialmente subalcalino segundo interpretação dos diagramas de Nachit et al e Rossi/Chevremont (Cf. A.C. MENDES, 1994, p.109-110).

Quadro nº 1 - Características do granito do Gerês (280¹1 M.A).

\begin{tabular}{|c|c|}
\hline "Mise en Place" & $\begin{array}{c}\text { Pós-Tectónicos (Carthónico -Pérmico) } \\
\text { Instalaçāo associada aos movimentos tardi-hercínicos. }\end{array}$ \\
\hline Génese & $\begin{array}{l}\text { Diferenciaçāo de um magma básico de origem infra-crustat } \\
\text { Granito d tipo I (Chappell c Whitc, 1974) }\end{array}$ \\
\hline $\begin{array}{l}\text { Compossiçāo Mincralógica } \\
\text { (variaçãăo percentual) }\end{array}$ & $\begin{array}{l}\text { Quirtzo: 32-24; Feldspato Políssico: 24-26; } \\
\text { Plagioclase: 34-36; Biotite: 4-6 }\end{array}$ \\
\hline $\begin{array}{l}\text { Composiçäo Quf́mica } \\
\text { (valores percentuais médios) }\end{array}$ & $\begin{array}{c}\mathrm{SiO} 2: 73,26 ; \mathrm{Al} 2 \mathrm{O} 3: 13,46 ; \mathrm{FeO}: 1,98 ; \mathrm{Na} 2 \mathrm{O}: 3,81 ; \mathrm{K} 2 \mathrm{O}: 4,87 \\
\mathrm{CaO}: 0,88 ; \mathrm{MgO}: 0,39 ; \mathrm{MnO}: 0,04 ; \mathrm{TiO} 2: 0,24 ; \mathrm{H} 2 \mathrm{O}: 0,74\end{array}$ \\
\hline Textura & Tendência porfiróide de grão médio a grosseiro \\
\hline $\mathrm{Cor}$ & Hololeuc(x)rata \\
\hline
\end{tabular}

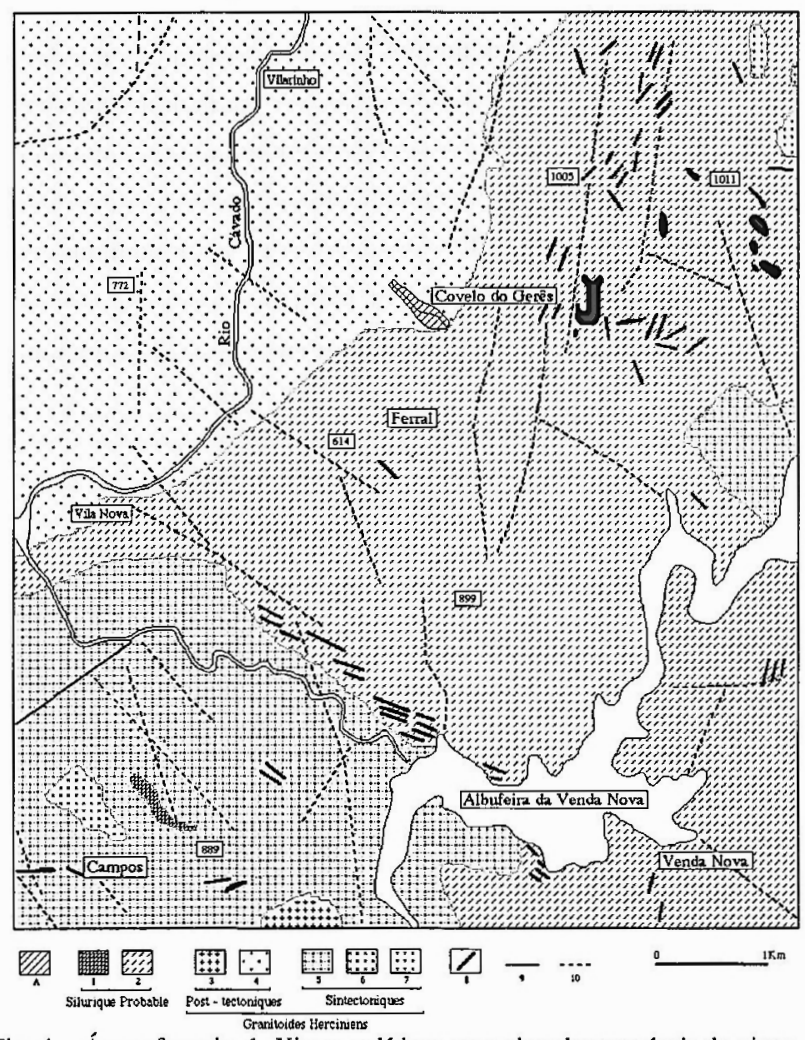

Fig. 4 - Área afectada; 1. Xistos pelíticos com abundantes níveis de xistos quartzíticos; 2. Xistos pelíticos com raros níveis de xistos quartzíticos; 3. Granito de Penedos; 4. Granito do Gerês; 5. Granito de Montalegre, Pondras e Borralha; 6. Granitóides de Sezelhe, Campos e Borralha; 7. Granito de Telhado; 8. Apelitos e/ou Pegmatitos; 9. Falha; 10. Fracturas. Fonte: Folha 6-A da Carta Geológica de Portugal. 


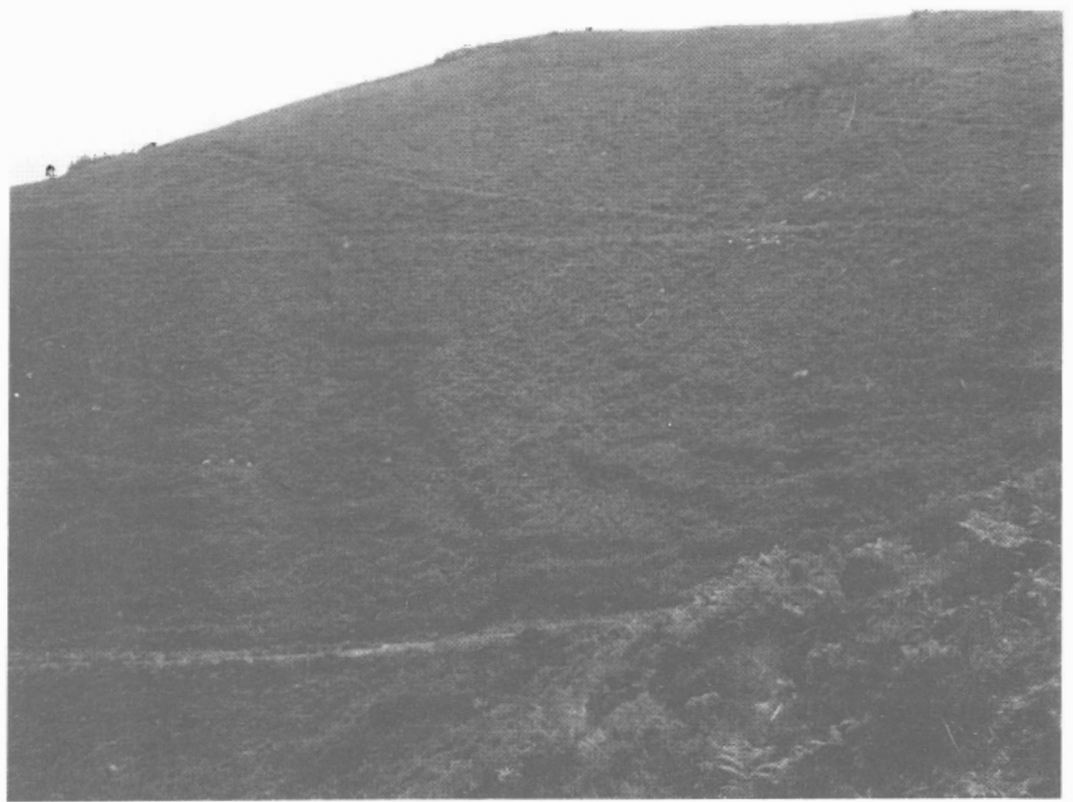

Fot. 3 - Fendas de descompressão resultantes do fluxo de detritos.

No âmbito do nosso trabalho, é fundamental assinalar o facto deste granito se encontrar extremamente alterado, para o que devem ter contribuído principalmente as suas características texturais e o grau de fracturação que evidencia, associadas às características hidroclimáticas da área. Aliás, refira-se a densa rede de fracturação manifesta em todo o maciço constituído pelo granito do Gerês, em que dominam os sistemas NNE-SSW eN-S, provavelmente correspondentes ao período de fracturação tardi-hercínica que controlou inclusivamente a sua instalação (A. RIBEIRO et al, 1979; N. FERREIRA et al, 1987).
Saliente-se ainda que, segundo Cotelo NEIVA (1966 b, p.9), um dos factores que facilitou a ocorrência do movimento teria sido precisamente a existência de várias falhas, uma das quais coincidiria com o local em que "(...) o terreno começou a ceder".

Embora na carta geológica não esteja registada esta observação, o trabalho de campo permite-nos assinalar a presença de uma rede de fracturação, que afecta, paralela e perpendicularmente, o sector em que se estabelece o contacto entre os metassedimentos e o granito, bem como toda a área envolvente. Esta rede de fracturas parece estar na origem do desenvolvimento de uma série de fendas que afectam o terreno

Fot. 4: Pormenor de fotografia 3 Patamar de abatimento a montante da cicatriz, ao longo da ravina

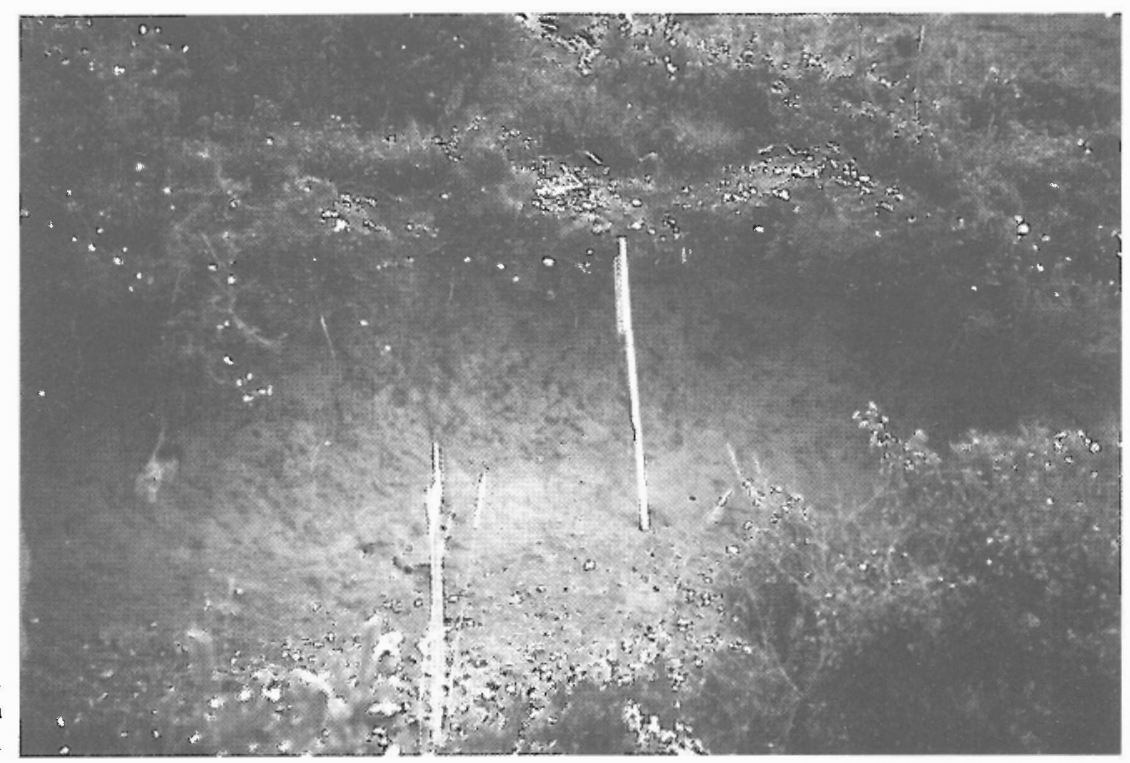




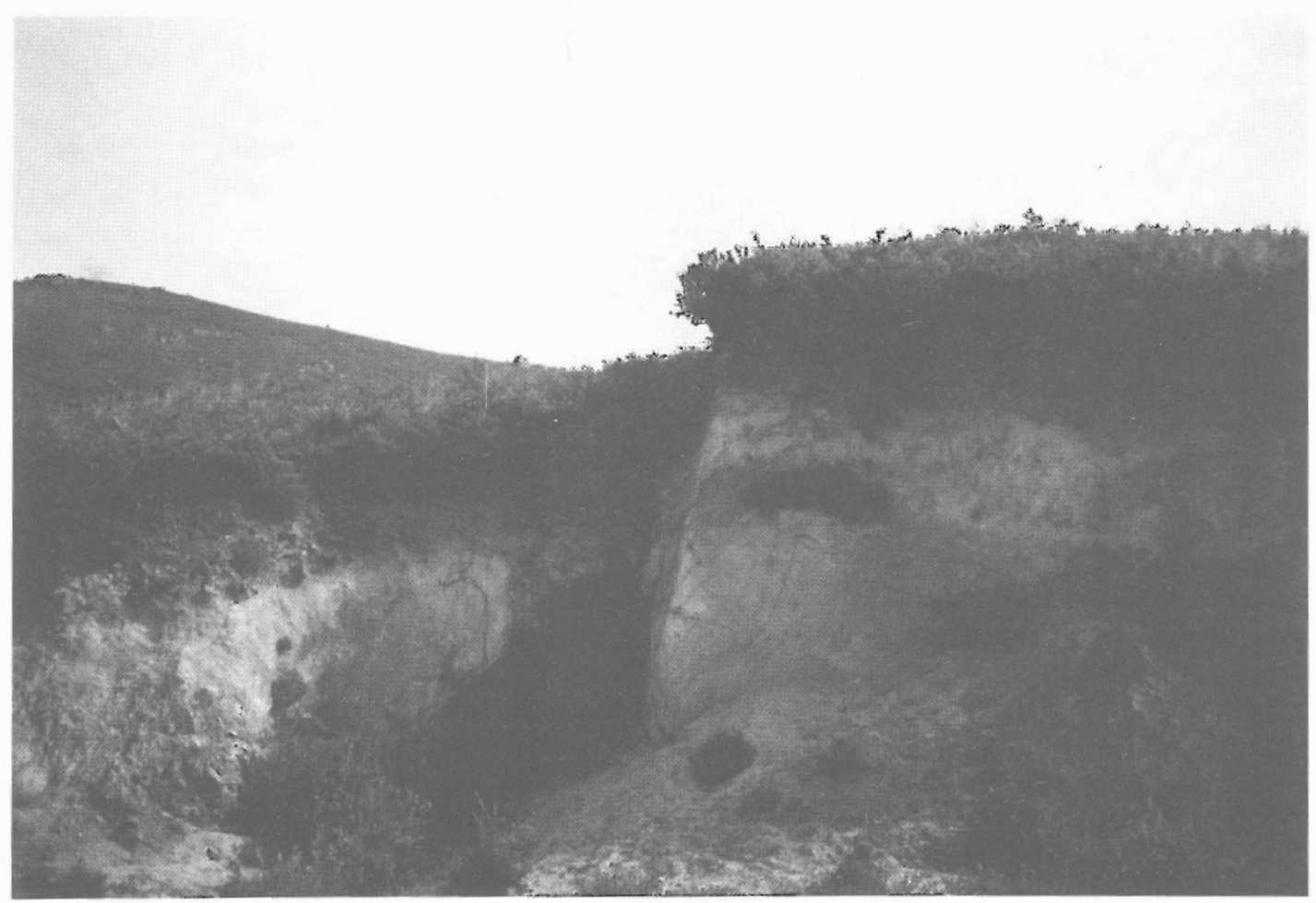

Fot. 5 - Detalle de um bloco de granito alterado que sofreu abatimento, a montante da cicatriz principal.

e assumem por vezes grandes dimensões (fot. 3,4 e 5), podendo ser agrupadas em dois tipos: fendas superficiais e fendas de grande profundidade. Estas últimas evidenciam uma forma irregular, dispondo-se próximo da cicatriz e constituindo uma rede complexa, que parece ter resultado do processo de descompressão no momento do movimento de massa ou imediatamente a seguir. Coincidindo com as áreas de fracturação, parecem resultar da separação lateral e abatimento de blocos rochosos, dado que o fluxo de detritos the retirou parte do suporte. Desenvolvem-se essencialmente nos metassedimentos do Silúrico e apresentamse grosseiramente paralelas ao contacto entre os metassedimentos e o granito, sugerindo que a profundidade resulta do aproveitamento da fracturação das rochas e da descontinuidade litológica local. Por outro lado, as fendas superficiais dispõem-se ao longo da ravina situada na margem direita da cicatriz principal, formando sucessivos degraus provavelmente resultantes de pequenos abatimentos de parte do depósito de fundo que preenche a ravina. Estes degraus são numerosos e apresentam desníveis por vezes superiores a $2 \mathrm{~m}$.

O fluxo de detritos, bem como a formação de ravinamentos que afectam outros sectores da vertente são, sem dúvida, facilitados pela já referida aiteração do granito do Gerês. Em toda a área, é possível observar perfis de alteração bastante espessos ${ }^{(2)}, 0$ que vai permitir uma eficaz infiltração da água (3).

Estes perfis são essencialmente constituídos por material alterado, que facilmente se desagrega evidenciando uma coloração branco-amarelada. Em alguns sectores mantém-se a estrutura da rocha inicial (arena de estrutura conservada), visível principalmente pelo facto de conservar a orientação dos megacristais de feldspato. Verifica-se ainda, macroscopicamente, que nesta massa subsistem principalmente os grãos de quartzo, enquanto os feldspatos se esboroam com facilidade e a biotite quase desaparece, evidenciando uma descoloração nítida.

A análise granulométrica de três amostras recolhidas na cicatriz (fig. 5), permite-nos verificar que nestes perfis há um nítido domínio da fracção arenosa (entre 2 e $0.0625 \mathrm{~mm}$ ), com uma percentagem média de 75\%, destacando-se o intervalo situado entre 1 e $0.5 \mathrm{~mm}$ (areia grosseira). Aliás, parece-nos importante referir que, em todas as amostras, mais de $90 \%$ do peso das partículas têm dimensão superior a $0.0625 \mathrm{~mm}$

(2) Embora seja difícil precisar a espessura que a alteração assume (só através de métodos geofísicos seria possível avaliar a sua profundidade concreta), podemos referir que na área onde se processou o movimento ela é provavelnente superior a 20 metros.

(3) De salientar, no entanto, que em alguns pontos, nomeadamente nas paredes laterais da cicatriz, se observam alguns afloramentos de granito pouco alterado, que poderăo ter funcionado como obstáculo a uma expansão lateral do movimento. 
Fig. 5: Curvas granulométricas de amostras do manto de alteração do granito do Gerês (cicatriz do fluxo).

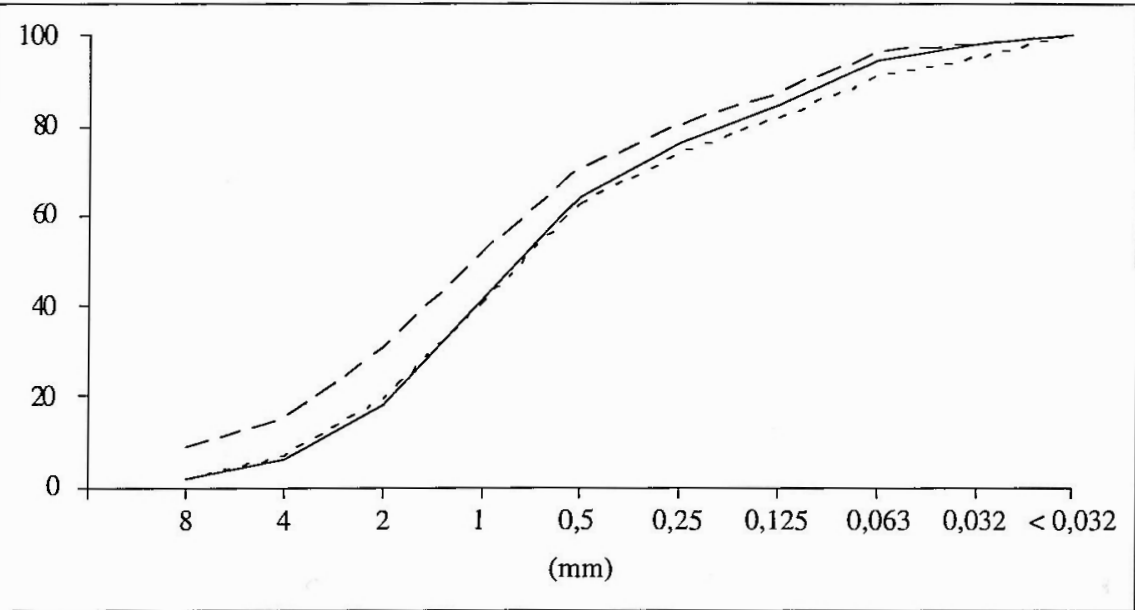

e entre $74 \%$ e $80 \%$, granulometria que excede os $0.25 \mathrm{~mm}$. Assim, torna-se evidente que os finos (silte e argila) assumem quantidades bastante diminutas, $o$ que se coaduna com dados obtidos a partir de estudos de vários perfis de alteração no Norte de Portugal.

Por outro lado, a identificação dos minerais argilosos, por difracção de raios-x, revela o predomínio do grupo da caulinite (caulinite e haloisite), com percentagens sempre superiores a $70 \%$.

A aparente contradição que existe entre o baixo teor de finos (que à partida poderia revelar uma alteração pouco intensa) e a presença de minerais argilosos do grupo da caulinite, revelando um grau de evolução geoquímico importante, poderá ser facilmente justificada por uma drenagem interna extremamente eficaz, associada às características dos próprios mantos de alteração. Com efeito, o facto de serem essencialmente constituídos por material arenoso permite uma rápida infiltração da água, que, atravessado o perfil, promove uma intensa lexiviação de iões e o transporte da fracção fina ( $M^{a}$. Amália BRAGA, 1988).

Mas, o que é importante reter desta análise, é que as características do material afectado pelo movimento, constituiram, sem sombra de dúvida, um factor primordial na justificação da sua ocorrência. Como refere Cotelo NEIVA (1966 a, p. 1), o facto do granito se encontrar "(...) muito alterado até grande profundidade, sendo a caulinização muito intensa," teria dado origem "à saturação do terreno devido a infiltraçôes provocadas por chuvas copiosas e de grande duração"o que teria permitido as várias movimentações.

Um elemento que parece apoiar tal observação, está associado aos próprios limites da área afectada: note-se que, para montante, o movimento interrompese precisamente quando atinge os metassedimentos; por outro lado, como já referimos, a sua expansão lateral parece ter sido bloqueada por afloramentos de granito pouco alterado. Em profundidade, o limite da área afectada parece coincidir com a menor alteração do granito, provocando a acumulação da água e a saturação dos materiais alterados.

\section{Condições geomorfológicas}

Covelo do Gerês localiza-se numa vertente situada entre os $450 \mathrm{~m}$ e os $850 \mathrm{~m}$ de altitude, em que a parte superior está talhada nos metassedimentos que se apresentam muito resistentes e a parte inferior é constituída pelo granito do Gerês muito alterado. Esta disposição dos afloramentos rochosos permitiu a conservação de uma vertente abrupta resultante do encaixe vigoroso da rede hidrográfica ao longo das fracturas mais importantes. O fluxo de detritos desenvolve-se, no essencial, no manto de alteração do granito e progride, para montante, até encontrar as rochas resistentes dos metassedimentos que vão funcionar como travão, sustendo o movimento. Neste caso, a evolução actual, tendente a diminuir o aspecto abrupto da vertente, foi travado pela disposição estrutural dos materiais.

Os declives desta vertente variam entre $10^{\circ} \mathrm{e}$ mais de $30^{\circ}$ (fig. 6). Nos sectores mais directamente afectados pelo movimento de massa são, no entanto, superiores a $20^{\circ} \mathrm{emesmo} 30^{\circ}$. Inclusivamente, próximo da cicatriz, bem como nos sectores onde domina o transporte sobre a acumulação, coincide com declives superiores a $30^{\circ}$.

O facto do processo ter ocorrido ao longo de uma ravina é um dos factores mais importantes. De facto, nela encontramos um depósito que corresponde a um preenchimento do fundo. Este depósito apresenta uma textura argilosa, de côr negra, com calhaus de granito e metassedimentos, por vezes decimétricos, dispostos de forma dispersa em todo o depósito. 
territorium $\quad 2.1995$
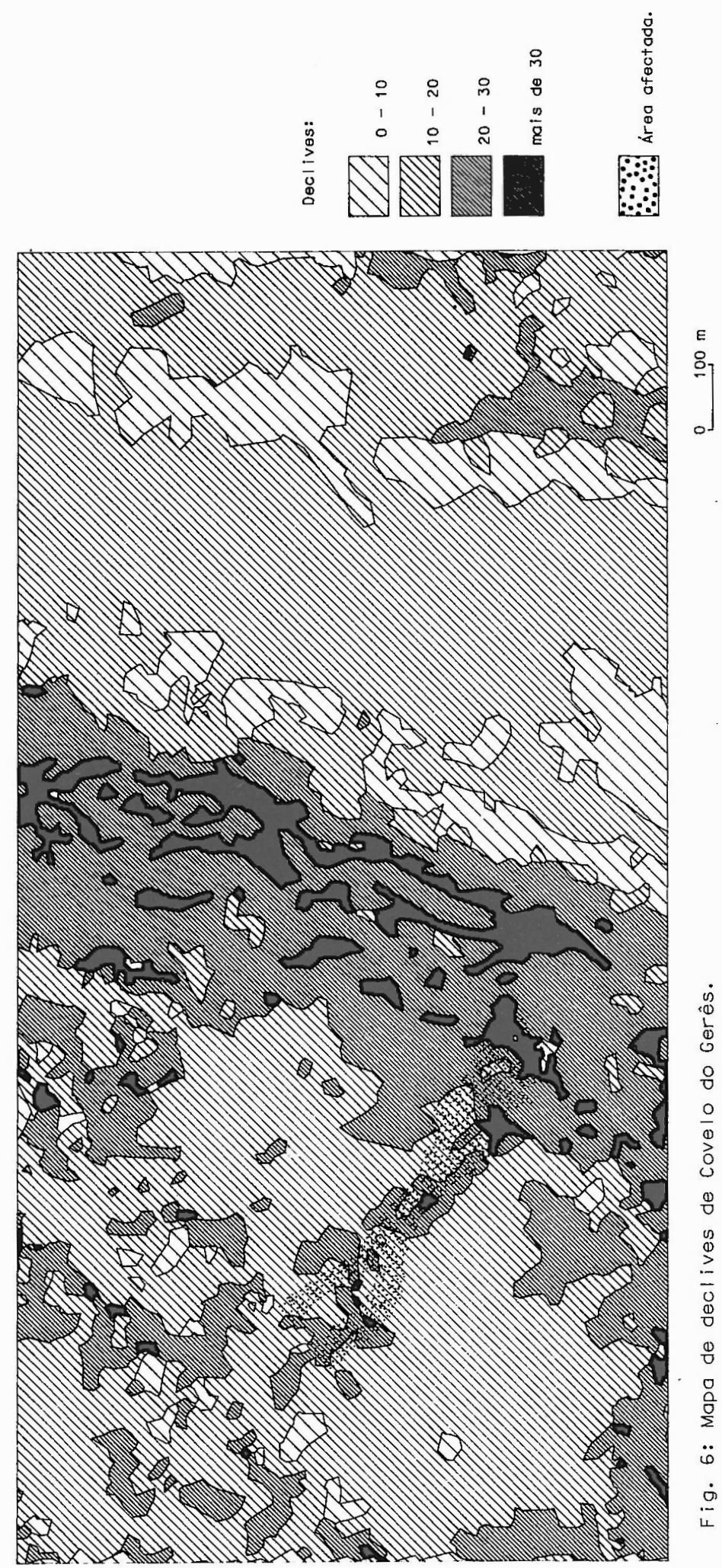
Com espessura variando entre um e dois metros na parte superior da ravina, é provável que fosse mais espesso junto à confluência com a ribeiro dos Novainhos. Este tipo de depósitoé observável noutras ravinas da mesma vertente e com espessura que chega a atingir quase três metros, a meia vertente. Foi, sem dúvida, a capacidade de retenção da água por este depósito, um dos factores que mais influiu no início do movimento dos materiais.

A área de Covelo do Gerês corresponde a um sector de densa fracturação, que influenciou directamente a capacidade de alteração dos granitos bem como permite uma fácil infiltração das águas ao longo dos planos de fragilidade locais.

\section{Condições hidroclimáticas}

Como vimos atrás, as condições de infiltração das águas ao longo da vertente foram facilitadas pela sua disposição estrutural, pela rede de fracturação e pelas características das formações superficiais.

No entanto, parece-nos que a capacidade de absorção da água pelo manto de alteração granítico foi totalmente preenchida. Pela descrição do processo feita atrás, ao tratarmos dos factores geológicos, somos levados a concluir que o processo se desencadeou pela saturação de um sector do manto de alteração na parte inferior da vertente. Este facto provocou a instabilidade da vertente que aparentava equilíbrio, embora precário. No início do movimento parece ter sido importante a grande concentração da água no manto de alteração originando a saturação do depósito de vertente que se sobrepunha e preenchia o fundo da ravina, provocando a sua ruptura.

Sendo as ravinas locais de convergência da drenagem ao longo das vertentes, parece que, quanto maiores forem estas formas, maiores serão as áreas por elas drenadase, portanto, maiores as concentrações de fluxo interno e externo. Deste modo, tornam-se locais privilegiados de instabilidade por saturação das formações superficiais aí existentes (J.C. FLAGEOLLET, 1989).

O estudo da precipitação do posto udométrico de Paradela do Rio aponta para valores elevados relativamente à média mensal. Em Fevereiro de 1966 registaram-se $856,6 \mathrm{~mm}$, muito acima dos valores médios mensais de 294,8 mm.

Em Paradela do Rio os registos para o mês de Fevereiro confirmam a existência de 19 dias consecutivos de precipitação, sendo que nos dias $8,9,10,12 \mathrm{e}$ 20 se registaram $73.7,97,73.7,88.5$ e $81 \mathrm{~mm}$, respectivamente (fig. 7 ). Em Janeiro há uma longa sequência chuvosa de 18 dias em que se salientam os dias 20,21 e 22 , com registos de $63.8,80.3$ e $102.8 \mathrm{~mm}$.

De uma forma geral, pode referir-se que, desde meados do mês de Janeiro ao até dia 25 de Fevereiro, as precipitações são abundantes, persistentes, atingindo valores extremamente elevados nalguns dias. As duas sequências chuvosas já referidas são separadas por um curto período (de 27 de Janeiro a 6 de Fevereiro) em que as precipitações, embora menos abundantes, persistem (neste período só quatro dias são secos).
Fig. 7 - Precipitações diárias e acumuladas para os meses de Dezembro de 1965 e Janeiro e Fevereiro de 1966, em Paradela do Rio $(6 \mathrm{~km}$ a Norte de Covelo do Gerês). As setas indicam os dias de ocorrência dos movimentos de massa.

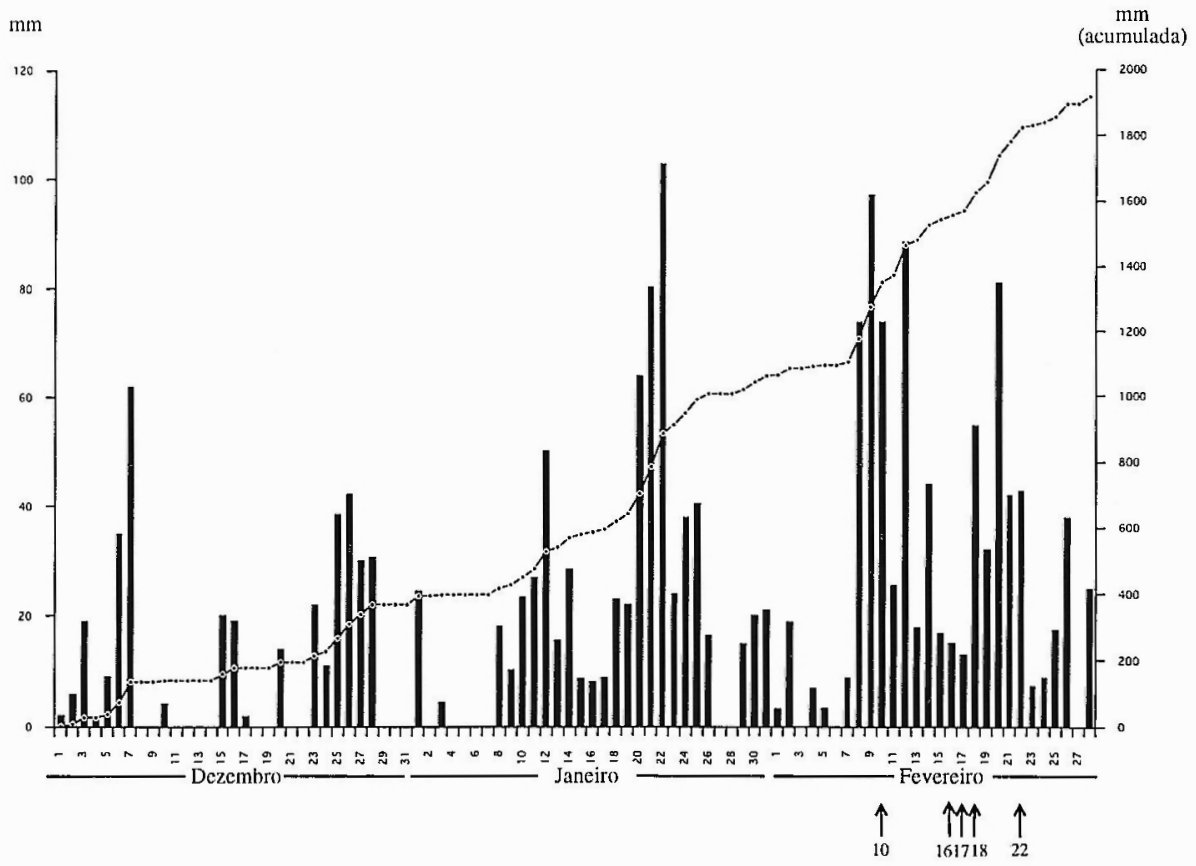


A análise dos valores da precipitação diária acumulada permite afirmar que o início da movimentação dos materiais coincide com um acréscimo da pressão da água infiltrada nas formaçōes superficiais (fig. 7). No entanto, a movimentação mais importante não ocorre no máximo das precipitações. Este facto permite deduzir que, uma vez destruída a estabilidade da vertente, é possível o desenvolvimento de processos geomorfológicos muito importantes desde que haja persistência de precipitação, mantendo elevada a pressão sobre os materiais do manto de alteração. Esta leitura parece confirmada pelas ocorrências do dia 17. No dia 18 volta a verificar-se novo acréscimo forte das precipitações $(54,5 \mathrm{~mm})$ mas os movimentos na vertente são considerados de menor importância. A última ocorrência (no dia 22 foi destruída outra casa) deu-se no fim de um período de precipitações importantes tendo, no dia 20 , chovido $81 \mathrm{~mm}$. Perto de se atingir novo ponto de equilíbrio, só novas precipitações abundantes permitiriam que um último movimento acontecesse. Mesmo assim, só dois dias depois do dia 20 ocorrem novos e importantes movimentos de terras (no dia 22 de Fevereiro).

\section{Conclusões}

Os processos de escoamento das águas nas vertentes concentram-se ao longo das ravinas. Este facto, aliado à diversidade de formas, variações de declives e intervenções humanas, parece constituir um conjunto de factores importante para explicar a grande complexidade deste tipo de processos, à semelhança do que ocorre noutras latitudes (A.M. JOHNSON e J.R. RODINE, 1984). No caso de Covelo do Gerês a complexidade do tipo de movimentação (dispersa por vários dias e com diferentes intensidades) reflecte a importância desigual dos vários factores a afectar o movimento. Com efeito, parece clara a importância das grandes precipitações diárias ao fim de um conjunto de dias muito chuvosos no desencadear do processo. A sua continuação parece depender da morfologia da vertente (declives fortes) e da estrutura e tipo dos materiais (manto de alteração) já que são propícios ao desenvolvimento de movimentos de massa, desde que seja alterada a estabilidade, muitas das vezes precária. Uma vez atingido novo ponto de equilíbrio, só a repetição de precipitações da ordem dos $81 \mathrm{~mm}$ a culminar uma série de dias muito chuvosos conseguiu o desenvolvimento de novo movimento dos materiais. Apesar de ainda não termos atingido declives mais fracos do topo da vertente, o recuo da cicatriz para montante foi retido pelo afloramento de metassedimentos muito resistentes. A partir dessa altura, deixaram de verificar-se fluxos de detritos a expensas do man- to de alteração do granito do Gerês e desenvolveu-se a queda de blocos junto da cicatriz principal.

Se a precipitaçãoé fundamental para a explicação do fluxo de Covelo do Gerês, não deixa de ser relevante a profunda e intensa alteração do granito do Gerês. Este facto permite uma fácil infiltração da água que se acumula quando encontra os sectores da rocha-mãe menos alterada. A fracturação tornou-se elemento importante, já que permitiu uma forte alteração do granito, facilitou a infiltração da água, bem como a circulação interna até atingir a rocha conservada. Uma vez impedida a infiltração, a água acumula-se, o que facilita a saturação do manto de alteração. A pressão torna-se muito forte promovendo a desestabilização da vertente. Desta forma se entende que os planos de deslizamento correspondam, em grande parte, aos planos de fracturação do granito.

Ao contrário de outros movimentos de massa no NW de Portugal, o de Covelo do Gerês foi constituído por uma sequência de fluxos distribuídos por vários dias. Esta característica poderia depender do ritmo das precipitações. No entanto, isso não parece ter ocorrido neste caso. Noutros casos (por exemplo, Cavez), a sequência chuvosa foi determinante, embora ajudada por uma intervenção humana desajustada das características do meio físico ${ }^{(4)}$. Em Covelo do Gerês a sequência chuvosa permitiu o desencadear do movimento, mas de imediato se fez sentir a influência de todas as condicionantes morfo-estruturais no prolongamento e posterior travagem de todo o processo de transporte de materiais ao longo da vertente. O início do movimento fez-se por pequenos deslizamentos, permitindo que a população abandonasse as habitações evitando-se a perda de vidas humanas. Neste caso, foram as pequenas movimentações de terras que desestabilizaram a vertente possibilitando o fluxo do dia 16 de Fevereiro.

Embora existam condições estruturais responsáveis pela ocorrência de grandes movimentos de massa no NW de Portugal, as ravinas constituem as formas que reunem as condições morfológicas mais propícias ao seu desenvolvimento. Estas formas constituem áreas preferenciais para ofluxo de detritos. Correspondendo a linhas de água de escoamento permanente, ou pelo menos estacional, são objecto de escolha para localização das habitações, moinhos e de poços para a rega. Facilmente se transformam em áreas de risco geomorfológico (M. PANNIZA, 1990).

Os impactes socio-económicos destes processos geomorfológicos são consideráveis já que a destruição de várias casas e de campos agrícolas em comunidades rurais de fracos meios económicos constituem pesada consequência, o que torna preocupante a ocupação destas áreas das vertentes.

(4) A drenagem de um eaminho concentrou o escoamento junto do local onde se verificou a ruptura dos materiais e a abertura da cicatriz. 


\section{BIBLIOGRAFIA:}

BATEIRA, C.V. e SOARES, L.M. (1992) - "O fluxo de detritos de Cavez. Um exemplo de movimento de massa na evolução actual de vertentes". Comunicação apresentada no VI Colóquio Ibérico de Geografia (no prelo).

BRAGA, Maria Amália Sequeira (1988) - Arenas e depósitos associados da bacia de drenagem do Rio Cávado (Portugal). Contribuição para o estudo da arenizaçāo. Dissertação de Doutoramento apresentada na Universidade doMinho, Braga, $325 \mathrm{p}$.

COUDÉ-GAUSSEN, G. (1981) - Les Serras da Peneda et do Gerês. Étude Géomorphologique, Lisboa, Memórias do CEG, $\mathrm{n}^{\circ} 5$, $254 \mathrm{p}$.

FERREIRA, N. et al (1987) - "Granitóides da Zona Centro Ibérica e seu enquadramento geodinâmico". Libro Homenage a L.C. Garcia Figuerola, Madrid, Edit. Rueda, Parte 1, Cap. 4, pp. 37-51.

FLAGEOLLET, J.-C. (1989) - Les mouvements de terrain et leur prévention. Paris, Ed. Masson, 224 p.

JOHNSON, A. M. e RODINE, J.R. (1984) - "Debris flow", in Slope Instability, cap. 8, Ed. Denys Brunsden e David Prior, Chichester, John Wiley \& Sons, pp. 257 a 361.

MENDES, A. Carreira (1994) - O maciço granítico de PenedaGerês. Petrologia, Mineralogia e Geoquímica. Provas de Aptidão Científica e Capacidade Pedagógica (policopiado), Braga.
NEIVA, J.Cotelo (1966a) - Desmoronamento de terreno em Covelo do Gerez. Relatório Técnico efectuado para a Hidro-Eléctrica do Cávado (policopiado).

NEIVA, J.Cotelo (1966b) - Geologia de Coveio do Gerez e seu interesse para localização de umaglomerado urbano. Relatório Técnico efectuado para a Hidro-Eléctrica do Cávado (policopiado).

NORONHA, F. e RIBEIRO, M.L. (1983) - Notícia Explicativa da Folha 6A - Montalegre, Lisboa, Serviços Geológicos de Portugal, $30 \mathrm{p}$.

PANIZZA, M. (1990) - "Geomorfologia applicata al rischio i all" impatto ambientali. Um esempio nelle dolomiti (Itália)". Actas da $1^{\circ}$ Reunión Nacional de Geomorfología, Vol.1, p.1-16, Teruel.

PEDROSA, A.S. e MARQUES, B.S. (1994) - "Man's action and slope erosion: A case study in Tâmega Basin (1981)". Territorium, 1, Coimbra, p. 23-34.

RIBEIRO, A. et al (1979) - Introduction à la géologie générale du Portugal. Lisboa, Serviços Geológicos de Portugal, 114 p.

RIBEIRO, M.L. (1983) - " Considerações sobre a génese dos diferentes granitos da região de Tourém-Montalegre-Gerês". Comun. Serv. Geol. Portugal, Lisboa, T. 69, Fasc. 1, pp. 37-45. 